\title{
Factor structure and psychometric properties of the english version of the trier inventory for chronic stress (TICS-E)
}

\author{
Katja Petrowski ${ }^{*}$ (D), Sören Kliem², Michael Sadler ${ }^{3}$, Alicia E. Meuret ${ }^{4}$, Thomas Ritz ${ }^{4}$ and Elmar Brähler ${ }^{5,6}$
}

\begin{abstract}
Background: Demands placed on individuals in occupational and social settings, as well as imbalances in personal traits and resources, can lead to chronic stress. The Trier Inventory for Chronic Stress (TICS) measures chronic stress while incorporating domain-specific aspects, and has been found to be a highly reliable and valid research tool. The aims of the present study were to confirm the German version TICS factorial structure in an English translation of the instrument (TICS-E) and to report its psychometric properties.

Methods: A random route sample of healthy participants $(N=483)$ aged $18-30$ years completed the TICS-E. The robust maximum likelihood estimation with a mean-adjusted chi-square test statistic was applied due to the sample's significant deviation from the multivariate normal distribution. Goodness of fit, absolute model fit, and relative model fit were assessed by means of the root mean square error of approximation (RMSEA), the Comparative Fit Index (CFI) and the Tucker Lewis Index (TLI).

Results: Reliability estimates (Cronbach's a and adjusted split-half reliability) ranged from .84 to .92 . Item-scale correlations ranged from .50 to .85. Measures of fit showed values of .052 for RMSEA ( $\mathrm{Cl}=0.50-.054)$ and .067 for SRMR for absolute model fit, and values of .846 (TLI) and .855 (CFI) for relative model-fit. Factor loadings ranged from .55 to .91 .

Conclusion: The psychometric properties and factor structure of the TICS-E are comparable to the German version of the TICS. The instrument therefore meets quality standards for an adequate measurement of chronic stress.
\end{abstract}

Keywords: Chronic stress, Questionnaire, Confirmatory factor analysis, Measurement invariance, Stress assessment

\section{Background}

Current stress research has identified an increased risk for acute and chronic illnesses as well as impaired physical health as a result of chronic stress [4, 23]. Sleep disorders [34], the acute coronary syndrome [31], and chronic pain [13] may occur in individuals confronted with chronic stress. Consequently, there is the need for further analysis of the concept of chronic stress and investigative instruments that provide more insight into its considerable relevance to the physical and mental health of individuals of all ages [16].

\footnotetext{
* Correspondence: katja.petrowski@uni-wh.de

${ }^{1}$ Witten/Herdecke University, Alfred-Herrhausen-Straße 50, 58448 Witten, Germany

Full list of author information is available at the end of the article
}

The concept of chronic stress is based on the frequency, intensity and duration of stressors [14]. Chronic stress is defined as the repeated occurrence of various intense stressors with uncontrollable consequences over a sustained period of time in the absence of adaptive coping mechanisms $[26,30]$. Chronic stress may also evolve from an individual's ongoing lack of satisfaction with the fulfillment of his or her needs, e.g., the need for appreciation, social support, meaningful tasks, and diversification [33] or from non-events, e.g., desires for a marriage proposal or pregnancy, which fail to materialize [38, 39].

Social roles may provide boundaries to conceptualize the large array of chronic stressors such as interpersonal relationships, activities, obligations, and responsibilities which affect most people, particularly with respect to their workplace and their roles in partnerships [12, 24, 28]. 
According to the Systemic Requirement Resource Model of Health [3], an individual's health may be promoted and preserved when the individual can depend on the availability of internal and external resources to satisfactorily deal with internal and external demands [36]. Internal demands are self-imposed based on an individual's own values, needs, and personal strivings. Available external resources can be societal, ecological, personal or occupational. Psychological resources may include personality traits such as sense of coherence, self-efficacy, self-reliance, resilience, and the competence to apply resources appropriately.

The Stressor-Appraisal-Health Model identifies factors which can influence vulnerability to stressors [21]. Actual and perceived control over role stressors, emotional and instrumental social support, and the personality or disposition of the role incumbent all can be modifying factors (e.g., type A, optimism, negative affect). These factors are presumed to alter the role incumbent's perceptions of role stressors and strengthen their ability to adapt successfully to role stressors [8]. In sum, individual health depends on the fulfillment of needs based on resources and modifier variables, and chronic stress may stem from the inability to cope with particular demands due to a lack of resources.

Theoretically, the impact of chronic stress is more relevant to the long-term development of illnesses than is the impact of acute stressors [22]. The human organism does not always habituate to chronic stressors lasting longer than 30 days, which may result in negative consequences for the immune system [17]. Experientially, there is no habituation; rather, higher levels of psychological distress symptoms are reported for stressors lasting up to one year [27].

Cohen et al. [10] provided an earlier overview of English-language assessment instruments for stress, e.g. the Perceived Stress Scale [9, 23]. However, chronic stress research mostly relies on life-event check-list measures. These scales provide a cumulative score based on either the number of events in a specific time frame or on the sum of the events' weights based on ratings by judges [23]. This approach does not differentiate types of chronic stressors and their intensities. Other assessment instruments focus solely on the magnitude of stress in single areas or settings such as the workplace ([6]; [20]) or the parent-child system [1]. These research tools examine specific domains more closely, making them useful for specific research questions. However, for chronic stress that results from the repeated occurrence of different stressors $[26,30]$ a comprehensive instrument that covers various relevant aspects may prove more useful. The German Trier Inventory for Chronic Stress (TICS; [35]) is the first instrument that explicitly captures chronic psychosocial stress employing nine factors: Work Overload, Social Overload, Pressure to Perform, Work Discontent, Excessive
Demands from Work, Lack of Social Recognition, Social Tensions, Social Isolation, and Chronic Worrying.

The authors of the TICS were inspired by Antonovsky [2] and other researchers who expanded the traditional model of risk factors by incorporating health protection aspects [11, 37]. They developed the Systemic Requirement - Resource Model of Health [3] in which individuals attempt to cope with external and internal demands by mobilizing external and internal resources. Thus, the model includes both the demands of the environment (private and work-related) as well as the demands that the person imposes upon the environment or him/herself. The resources implemented for these kinds of demands are in line with the multi-level model of physical and psychological resources (ecological, social, private and job-related, [3]). The nine factors of the TICS were developed in accordance with the Systemic Requirement - Resource Model of Health [3]. These factors can be grouped into High Demands referring to specific job conditions and social conditions, and Lack of Satisfaction of one's needs due to unsatisfactory job conditions and social conditions [35]. As the TICS scales were developed based on the Systemic Requirement - Resource Model of Health [3], the authors postulated content validity as a logical consequence [35].

The factorial structure of the German TICS version, consisting of 57 items loading on nine factors was demonstrated in a sample of $N=604$ adults (aged 16 to 70), who were randomly selected from telephone registers based on calculations of representative numbers of participants from the statistics of the German Federal Statistical Office for 1999 [35]. The authors of the TICS found a nine-factor model based on the item values and a twofactor model based on the sum scores of the nine scales [35]. Petrowski, Paul, Albani, \& Brähler [29] subsequently replicated the psychometric properties and the factorial structure using a large representative German sample.

At present, there is no English-language questionnaire available to investigate chronic stress, that would fulfill the qualitative criteria of the German TICS [29]. A translated English-language version of the TICS might therefore be a valuable addition to the existing research tools for chronic stress. The aim of this research was to examine the quality criteria of the translated Englishlanguage version of the TICS with respect to its factorial structure and psychometric properties. In order to allow optimal comparison across language versions of the TICS we aimed at close correspondence with the German version of the TICS and did not plan to reduce the overall length of the instrument.

\section{Methods}

Sample

The data was collected at two college campuses in the Eastern and Southeastern region of the USA. Participants 
were undergraduate introductory psychology students who contributed in return for course credit. The final pooled sample of $N=483$ participants with a mean age of $M=19.96$ years $(S D=2.79$, range $=18-30$ years $)$ included $75.6 \%$ female participants $(N=365)$. The participants were Caucasian (80.8\%), African American (4.5\%), Latino (1.2\%), Asian American (5.2\%), and other (6.4\%). They received a data protection declaration that is in agreement with the Helsinki Declaration. The study was approved by the institutional review boards of the involved university institutions and all participants provided written informed consent.

\section{Instruments}

The Trier Inventory for Chronic Stress (TICS) is a standardized German questionnaire that has been tested with respect to its factorial structure and psychometric properties, showing good to very good reliability [29]. Internal consistency (Cronbach's Alpha, $\alpha$ ) was good to very good with values ranging from .84 to .91 (mean of $\alpha=.87$ ) [35]. Nine interrelated factors of chronic stress are assessed: Work Overload; Social Overload; Pressure to Perform; Work Discontent; Excessive Demands at Work; Lack of Social Recognition; Social Tensions; Social Isolation; Chronic Worrying. The nine factors were derived from 57 items rated on a five-point rating scale (0-4, labeled as: "never", "rarely", "sometimes", "frequently", "always"). Participants rated the occurrence/frequency of specific situations with a recall period of the previous three months. In addition, 12 items were summed for a screening scale.

The TICS was translated into English in accordance with the INTERNATIONAL TEST COMMISSION (ITC) Guidelines for Translating and Adapting Tests [19]. The items were translated from German to English by one bilingual expert and then backtranslated to German by a second bilingual expert. Comparison and reconciliation of the original and back-translated items was carried out by a group of experts, followed by a second round of forward and back-translation. Sample items from each scale of the TICS-E are listed in Table 1.

\section{Statistical procedure}

Internal consistency (Cronbach's $\alpha$ ) and split-half reliabilities were calculated for each of the TICS-E subscales. Skew and kurtosis were calculated on the itemand subscale-levels, and tests of normality (Shapiro-Wilk test) were performed. To determine item selectivity, the correlation of each item was computed with the remaining items on the respective scale (item-rest correlations). The main aim of this study was to examine the factorial validity of the TICS-E: A nine-factor model was examined using confirmatory factor analysis (CFA) with all items loading on their designated factor [29]. Due to significant deviations from the multivariate normal distribution, the robust maximum likelihood estimation (MLM) with a mean-adjusted chi-square test statistic (Satorra-Bentler $\mathrm{X}^{2}$ ) was applied, which has been shown to be robust to violations of normality [7]. To evaluate the goodness of fit of the relevant model, four different (Satorra-Bentler.scaled) criteria were considered: the root mean square error of approximation (RMSEA.scaled), standardized root mean square residual (SRMR.scaled), and the $90 \%$ confidence interval to the absolute model fit. In addition, two criteria (the Comparative Fit-Index [CFI.scaled] and the Tucker Lewis Index [TLI.scaled]) were calculated to measure the relative model-fit compared to the "null" model. RMSEA values $<.050$ represent a "close fit", RMSEA values between .050 and .080 represent a "reasonably close fit", and RMSEA values > .100 represent an "unacceptable model" [5]. The SRMR with values less than 0.10 , or of 0.08 (for a more conservative version; see [18]), are considered to represent a good fit. Regarding CFI and TLI, Hu and Bentler [18] suggested a CFI and TLI $>.950$ for a good model fit. Data analysis was carried out in R. The R package Latent Variable Analysis (lavaan); [32]) was used for the CFAs.

Table 1 Sample TICS-E Items with scale allocation

\begin{tabular}{lll}
\hline Item number & Item & Scale \\
\hline 45 & Arguments I get involved in frequently become lasting conflicts & Social Tensions \\
46 & I feel that my performance is not recognized enough & Lack of Social Recognition \\
54 & I feel overwhelmed by my tasks & Work Overload \\
55 & In spite of the effort I make, I am unable to manage my tasks properly & Excessive Demands from Work \\
57 & Sometimes I feel overburdened by my responsibilities toward others & Social Overload \\
37 & I must meet responsibilities which I am adamantly opposed to & Work Discontent \\
25 & Sometimes I am consumed by my worries & Chronic Worrying \\
29 & Sometimes I lack the opportunity to articulate my concerns I have & Social Isolation \\
40 & no opportunity to discuss things with others & Pressure to Perform \\
\hline
\end{tabular}


Table 2 TICS-E scale properties for the total sample

\begin{tabular}{|c|c|c|c|c|c|c|c|c|c|c|}
\hline \multirow[b]{2}{*}{ Scale } & \multirow[b]{2}{*}{ Items } & \multirow[b]{2}{*}{ Range $^{a}$} & \multicolumn{3}{|l|}{ Reliabilities } & \multicolumn{5}{|c|}{$\begin{array}{l}\text { Total sample } \\
N=484\end{array}$} \\
\hline & & & Cronbach's a & Split- half ${ }^{b}$ & $r_{\text {it }}$ range & $\bar{M}$ & SD & Skewness & Kurtosis & W \\
\hline Work Overload & 8 & $\begin{array}{l}0-31 \\
(0-32)\end{array}$ & .89 & .86 & $.59-.78$ & 15.60 & 6.26 & -0.20 & 0.38 & $0.99^{* *}$ \\
\hline Social Overload & 6 & $\begin{array}{l}0-24 \\
(0-24)\end{array}$ & .87 & .85 & $.62-.72$ & 8.15 & 5.08 & 0.29 & -0.33 & $0.97^{* * *}$ \\
\hline Pressure to Perform & 9 & $\begin{array}{l}0-35 \\
(0-36)\end{array}$ & .86 & .84 & $.50-.68$ & 17.64 & 6.23 & -0.60 & 0.7 & $0.97^{* * *}$ \\
\hline Work Discontent & 8 & $\begin{array}{l}0-32 \\
(0-32)\end{array}$ & .86 & .85 & $.56-.67$ & 11.83 & 5.55 & 0.14 & 0.02 & $0.99^{* * *}$ \\
\hline Excessive Demands at Work & 6 & $\begin{array}{l}0-24 \\
(0-24)\end{array}$ & .85 & .84 & $.52-.74$ & 7.88 & 4.50 & 0.36 & -0.12 & $0.98^{* * *}$ \\
\hline Lack of Social Recognition & 4 & $\begin{array}{l}0-16 \\
(0-16)\end{array}$ & .87 & .87 & $.67-.80$ & 5.36 & 3.14 & 0.32 & 0.05 & $0.97^{* * *}$ \\
\hline Social Tensions & 6 & $\begin{array}{l}0-24 \\
(0-24)\end{array}$ & .88 & .86 & $.62-.75$ & 5.81 & 4.26 & 0.57 & 0.05 & $0.95^{* * *}$ \\
\hline Social Isolation & 6 & $\begin{array}{l}0-24 \\
(0-24)\end{array}$ & .87 & .86 & $.50-.77$ & 8.85 & 4.90 & 0.35 & 0.11 & $0.98^{* * *}$ \\
\hline Chronic Worrying & 4 & $\begin{array}{l}0-16 \\
(0-16)\end{array}$ & .91 & .91 & $.65-.85$ & 6.80 & 4.17 & 0.26 & -0.59 & $0.97^{* * *}$ \\
\hline Chronic Stress Screening Scale & 12 & $\begin{array}{l}0-46 \\
(0-48)\end{array}$ & .92 & .82 & $.52-.78$ & 19.87 & 9.43 & 0.08 & -0.20 & $0.99 * * *$ \\
\hline
\end{tabular}

Note. ${ }^{a}$ possible range of values in parentheses; ${ }^{b}$ Split-half reliabilities adjusted according to Spearman-Brown; $\boldsymbol{r}_{\boldsymbol{i t}}$ range Range of item-scale correlations, $W$ Test statistic related to the Shapiro-Wilk test

** $=.05 ; * * * 001$

\section{Results}

\section{Descriptive item analysis}

Table 2 displays the means and standard deviations of the TICS-E subscales separately by gender, as well as the range of the selectivity values $\left(r_{i t}\right)$ for the TICS-E items. Significant univariate non-normality was detected with the Shapiro-Wilk test for all subscales. Table 3 shows the moderate to high inter-correlations between the
TICS-E subscales, TICS-E total score, and TICS-Escreening scale.

\section{Reliability estimates}

As may be seen in Table 2, internal consistencies (Cronbach's $\alpha$ ) were good to very good and the adjusted split-half reliabilities ranged from .84 to .92 . Table 3

Table 3 Intercorrelations of scales (upper matrix) and standardized factor covariances (lower matrix) of the English-language version of the TICS

\begin{tabular}{|c|c|c|c|c|c|c|c|c|c|c|}
\hline Scale & $\begin{array}{l}\text { Work } \\
\text { Overload }\end{array}$ & $\begin{array}{l}\text { Social } \\
\text { Overload }\end{array}$ & $\begin{array}{l}\text { Pressure to } \\
\text { Perform }\end{array}$ & $\begin{array}{l}\text { Work } \\
\text { Discontent }\end{array}$ & $\begin{array}{l}\text { Excessive } \\
\text { Demands } \\
\text { at Work }\end{array}$ & $\begin{array}{l}\text { Lack of Social } \\
\text { Recognition }\end{array}$ & $\begin{array}{l}\text { Social } \\
\text { Tensions }\end{array}$ & $\begin{array}{l}\text { Social } \\
\text { Isolation }\end{array}$ & $\begin{array}{l}\text { Chronic } \\
\text { Worrying }\end{array}$ & $\begin{array}{l}\text { Chronic Stress } \\
\text { Screening Scale }\end{array}$ \\
\hline Work Overload & - & .54 & .66 & .56 & .74 & .58 & .37 & .49 & .63 & .83 \\
\hline Social Overload & .61 & - & .60 & .58 & .56 & .61 & .54 & .44 & .47 & .64 \\
\hline Pressure to Perform & .74 & .69 & - & .61 & .54 & .54 & .42 & .53 & .55 & .67 \\
\hline Work Discontent & .61 & .66 & .68 & - & .7 & .68 & .58 & .67 & .55 & .68 \\
\hline $\begin{array}{l}\text { Excessive Demands } \\
\text { at Work }\end{array}$ & .84 & .64 & .63 & .81 & - & .72 & .55 & .59 & .65 & .84 \\
\hline Lack of Social Recognition & .63 & .70 & .60 & .78 & .82 & - & .59 & .53 & .58 & .76 \\
\hline Social Tensions & .40 & .62 & .46 & .67 & 62 & .67 & - & .50 & .38 & .51 \\
\hline Social Isolation & .53 & .48 & .58 & .76 & .67 & .57 & .54 & - & .57 & .65 \\
\hline Chronic Worrying & .69 & .51 & .60 & .57 & .71 & .60 & .39 & .59 & - & .90 \\
\hline \multicolumn{10}{|c|}{ Chronic Stress Screening Scale } & - \\
\hline
\end{tabular}


Table 4 Item-scale correlation and factor loadings for the items of the English version of the TICS

\begin{tabular}{|c|c|c|c|c|c|c|c|c|c|c|c|}
\hline \multirow[b]{2}{*}{ Item } & \multirow[b]{2}{*}{ M } & \multirow[b]{2}{*}{ SD } & \multirow[b]{2}{*}{ Skewness } & \multirow[b]{2}{*}{ Kurtosis } & \multirow[b]{2}{*}{ W } & \multicolumn{6}{|l|}{ 9-factor model } \\
\hline & & & & & & Factor & $\begin{array}{l}\text { Factor } \\
\text { loading }\end{array}$ & $\begin{array}{l}\text { Standardized } \\
\text { error variances }\end{array}$ & Factor & $\begin{array}{l}\text { Factor } \\
\text { loading }\end{array}$ & $\begin{array}{l}\text { Standardized } \\
\text { error variances }\end{array}$ \\
\hline & & & & & & Work Overload & & & High Demand & & \\
\hline 01 & 2.20 & 0.96 & -0.45 & -0.23 & 0,89 & & 62 & .62 & & .57 & .68 \\
\hline 04 & 1.74 & 1.04 & 0.17 & -0.53 & 0.91 & & .62 & .62 & & .57 & .68 \\
\hline 17 & 1.33 & 1.06 & 0.45 & -0.50 & 0.89 & & .63 & .60 & & .61 & .63 \\
\hline 27 & 2.16 & 1.07 & -0.26 & -0.46 & 0.91 & & 60 & .64 & & .60 & .64 \\
\hline 38 & 1.80 & 1.05 & -0.11 & -0.62 & 0.91 & & .77 & .41 & & .74 & .45 \\
\hline 44 & 2.18 & 1.05 & -0.26 & -0.35 & 0.91 & & .80 & .36 & & .69 & .52 \\
\hline 50 & 1.90 & 1.06 & 0.02 & -0.50 & 0.91 & & .79 & .38 & & .68 & .54 \\
\hline \multirow[t]{2}{*}{54} & 2.29 & 1.05 & -0.31 & -0.34 & 0.91 & & .83 & .31 & & .72 & .48 \\
\hline & & & & & & Social Overload & & & & & \\
\hline 07 & 1.39 & 1.16 & 0.49 & -0.63 & 0.89 & & .66 & .56 & & .54 & .71 \\
\hline 19 & 1.57 & 1.10 & 0.27 & -0.66 & 0.91 & & .78 & .39 & & .68 & .54 \\
\hline 28 & 1.30 & 1.03 & 0.54 & -0.21 & 0.88 & & .74 & .45 & & .59 & .65 \\
\hline 39 & 1.43 & 1.12 & 0.40 & -0.57 & 0.89 & & .77 & .41 & & .63 & .60 \\
\hline 49 & 1.23 & 1.11 & 0.58 & -0.46 & 0.87 & & .66 & .56 & & .53 & .72 \\
\hline \multirow[t]{2}{*}{57} & 1.24 & 1.04 & 0.47 & -0.51 & 0.88 & & .72 & .48 & & .61 & .63 \\
\hline & & & & & & Pressure to Perform & & & & & \\
\hline 08 & 1.49 & 0.99 & 0.16 & -0.50 & 0.90 & & .55 & .70 & & .55 & .70 \\
\hline 12 & 1.86 & 1.01 & 0.00 & -0.42 & 0.91 & & .60 & .64 & & .54 & .71 \\
\hline 14 & 1.54 & 0.97 & 0.14 & -0.51 & 0.90 & & .55 & .70 & & .55 & .70 \\
\hline 22 & 1.99 & 1.02 & -0.21 & -0.34 & 0.90 & & .73 & .47 & & .65 & .58 \\
\hline 23 & 2.40 & 0.97 & -0.55 & 0.28 & 0.88 & & .59 & .65 & & .46 & .79 \\
\hline 30 & 1.68 & 1.00 & 0.00 & -0.50 & 0.90 & & .58 & .66 & & .52 & .73 \\
\hline 32 & 2.51 & 1.00 & -0.61 & 0.22 & 0.88 & & .64 & .59 & & .55 & .70 \\
\hline 40 & 2.14 & 1.07 & -0.36 & -0.36 & 0.91 & & .75 & .44 & & .69 & .52 \\
\hline \multirow[t]{2}{*}{43} & 1.49 & 0.99 & 0.16 & -0.50 & 0.90 & & .71 & .50 & & .66 & .56 \\
\hline & & & & & & Work Discontent & & & Lack of Satisfaction & & \\
\hline 05 & 2.02 & 0.98 & -0.19 & -0.25 & 0.90 & & .57 & .68 & & .50 & .75 \\
\hline 10 & 1.29 & 1.06 & 0.50 & -0.40 & 0.88 & & .67 & .55 & & .61 & .63 \\
\hline 13 & 2.07 & 0.86 & -0.19 & 0.15 & 0.88 & & .60 & .64 & & .55 & .70 \\
\hline 21 & 1.23 & 0.92 & 0.43 & -0.08 & 0.87 & & .73 & .47 & & .66 & .56 \\
\hline 37 & 1.18 & 0.99 & 0.49 & -0.51 & 0.87 & & .69 & .52 & & .67 & .55 \\
\hline 41 & 1.05 & 0.88 & 0.58 & 0.01 & 0.85 & & .69 & .52 & & .62 & .62 \\
\hline 48 & 1.38 & 1.01 & 0.35 & -0.36 & 0.89 & & 68 & .54 & & .62 & .62 \\
\hline \multirow[t]{2}{*}{53} & 1.61 & 1.07 & 0.12 & -0.67 & 0.91 & & .67 & .55 & & .64 & .59 \\
\hline & & & & & & Excessive Demand & & & & & \\
\hline 03 & 1.46 & 0.96 & 0.35 & -0.18 & 0.89 & & .70 & .51 & & .62 & .62 \\
\hline 20 & 1.19 & 0.97 & 0.66 & 0.23 & 0.87 & & .69 & .52 & & .64 & .59 \\
\hline 24 & 0.67 & 0.86 & 1.14 & 0.64 & 0.75 & & .57 & .68 & & .55 & .70 \\
\hline 35 & 1.36 & 0.91 & 0.21 & -0.31 & 0.88 & & .70 & .51 & & .67 & .55 \\
\hline 47 & 1.80 & 1.16 & 0.13 & -0.73 & 0.91 & & .75 & .44 & & .70 & .51 \\
\hline 55 & 1.39 & 1.06 & 0.46 & -0.46 & 0.89 & & .80 & .36 & & .73 & .47 \\
\hline
\end{tabular}


Table 4 Item-scale correlation and factor loadings for the items of the English version of the TICS (Continued)

\begin{tabular}{|c|c|c|c|c|c|c|c|c|c|c|c|}
\hline \multirow[b]{2}{*}{ Item } & \multirow[b]{2}{*}{ M } & \multirow[b]{2}{*}{ SD } & \multirow[b]{2}{*}{ Skewness } & \multirow[b]{2}{*}{ Kurtosis } & \multirow[b]{2}{*}{ W } & \multicolumn{6}{|c|}{ 9-factor model } \\
\hline & & & & & & Factor & $\begin{array}{l}\text { Factor } \\
\text { loading }\end{array}$ & $\begin{array}{l}\text { Standardized } \\
\text { error variances }\end{array}$ & Factor & $\begin{array}{l}\text { Factor } \\
\text { loading }\end{array}$ & $\begin{array}{l}\text { Standardized } \\
\text { error variances }\end{array}$ \\
\hline & & & & & & Lack of & & & & & \\
\hline 02 & 1.64 & 0.87 & 0.00 & -0.22 & 0.88 & & .72 & .48 & & .64 & .59 \\
\hline 18 & 1.13 & 0.90 & 0.54 & 0.01 & 0.86 & & .80 & .36 & & .72 & .48 \\
\hline 31 & 1.26 & 0.92 & 0.40 & -0.12 & 0.88 & & .86 & .26 & & .72 & .48 \\
\hline \multirow[t]{2}{*}{46} & 1.33 & 1.00 & 0.42 & -0.25 & 0.89 & & .81 & .34 & & .73 & .47 \\
\hline & & & & & & Social T & & & & & \\
\hline 06 & 1.24 & 0.86 & 0.34 & -0.30 & 0.87 & & .73 & .47 & & .57 & .68 \\
\hline 15 & 1.06 & 0.89 & 0.50 & -0.31 & 0.86 & & .72 & .48 & & .54 & .71 \\
\hline 26 & 0.71 & 0.90 & 1.19 & 0.95 & 0.76 & & .67 & .55 & & .50 & .75 \\
\hline 33 & 1.01 & 0.95 & 0.88 & 0.57 & 0.84 & & .72 & .48 & & .56 & .69 \\
\hline 45 & 0.84 & 0.90 & 0.94 & 0.51 & 0.81 & & .82 & .33 & & .60 & .64 \\
\hline \multirow[t]{2}{*}{52} & 0.96 & 0.92 & 0.75 & 0.07 & 0.84 & & .76 & .42 & & .54 & .71 \\
\hline & & & & & & Social is & & & & & \\
\hline 11 & 1.34 & 1.04 & 0.51 & -0.35 & 0.89 & & .74 & .45 & & .57 & .68 \\
\hline 29 & 1.39 & 1.00 & 0.41 & -0.25 & 0.89 & & .58 & .66 & & .62 & .62 \\
\hline 34 & 1.45 & 1.06 & 0.22 & -0.68 & 0.90 & & .80 & .36 & & .63 & .60 \\
\hline 42 & 1.28 & 1.00 & 0.52 & -0.19 & 0.88 & & .83 & .31 & & .61 & .63 \\
\hline 51 & 1.68 & 1.03 & 0.07 & -0.47 & 0.91 & & .72 & .48 & & .55 & .70 \\
\hline \multirow[t]{2}{*}{56} & 1.70 & 1.17 & 0.15 & -0.75 & 0.91 & & .72 & .48 & & .61 & .63 \\
\hline & & & & & & Chronic & & & & & \\
\hline 09 & 1.54 & 1.12 & 0.33 & -0.63 & 0.90 & & .68 & .54 & & .67 & .55 \\
\hline 16 & 1.85 & 1.20 & 0.08 & -0.87 & 0.91 & & .89 & .21 & & .64 & .59 \\
\hline 25 & 1.69 & 1.18 & 0.22 & -0.78 & 0.91 & & .90 & .19 & & .66 & .56 \\
\hline 36 & 1.72 & 1.21 & 0.25 & -0.83 & 0.91 & & .91 & .17 & & .67 & .55 \\
\hline
\end{tabular}

presents item-scale correlations which ranged from $\mathrm{r}_{\mathrm{it}}=.50$ to .85 . The item means were in the expected range.

\section{Confirmatory factor analysis}

A CFA with items loading on the 9 relevant factors resulted in an adequate fit regarding RMSEA.scaled $=.052$ $(\mathrm{CI}=.050-.054)$ and SRMR.scaled $=.067$ and an unacceptable comparative fit according to the TLI.scaled $=.846$ and CFI.scaled $=.855$. However, the model fits are comparable in structure to the results obtained by Petrowski et al. [29] with the German version of the TICS (TLI $=.855$, $\mathrm{CFI}=.863, \mathrm{SRMR}=.071$, RMSEA $=.051$ ). Table 3 shows the estimated inter-factor correlations based on the results of the CFA. Factor-loadings are presented in Table 4, ranging from .55 to .91 .

We also analyzed the aforementioned two factor model. This model resulted in an inadequate fit according to RMSEA.scaled $=.079(\mathrm{CI}=.077-.081)$ and SRMR.scaled $=$ 0.080 and an unacceptable comparative fit according to the
TLI.scaled $=.644$ and CFI.scaled $=.080$. Overall the twofactor solution did not meet any of the common tests of model fit. Factor-loadings are also presented in Table 4, ranging from .46 to .74 .

\section{Discussion}

Our findings indicate that the translated version of the German TICS shows good reliability and an adequate fit for the nine-factorial model based on CFA.

\section{Confirmatory factor analysis (CFA)}

The 9-factor model was previously found to be superior to the 2-factor model of the TICS [29]. The 9-factor model in the present English version of the TICS (TICS-E) produced some fit indices of CFA comparable to the earlier replication study of the German version [29], specifically the RMSEA and SRMR of the TICS-E indicated an adequate model fit [15]. On the other hand, the TLI and CFI values of the TICS-E showed an unacceptable comparative fit according to the guidelines of $\mathrm{Hu}$ \& Bentler [18]. These 
lower values align with the TLI and CFI results found for the German version of the TICS [29]. These mixed results might be accounted for by the large number of nine different factors [29], as well as the inability of large questionnaire data to fully meet the recommendations for goodness-of-fit suggested by $\mathrm{Hu} \&$ Bentler [18] and Marsh, Hau, \& Wen [25]. Some factor loadings (Table 3) were in the area of .5 but most were greater than .7. Thus, all items were strongly related to their associated latent constructs. [15]. For practical use, both the nine individual subscales and the total score can be used. The inter-correlations between subscales ranged between .37 to .90 , which was higher than for the original results with the German TICS version $r=.15$ to .63 [35]. However, the inter-correlations were in the same range as in the replication study of the German TICS (ranging from $r=.30$ to .77; [29]). The factorial structure of the TICS-E could also be replicated with a model fit similar to the original German version.

\section{Reliability and descriptive scale analysis}

The TICS-E showed good to very good internal consistency and reliability (Cronbach's $\alpha=.84-.92$; splithalf reliabilities $r=.82-.91$ ). The relevant values aligned well with the results as published in the original TICS manual by Schulz et al. [35] (Cronbach's $\alpha=.84$ to.91). Although the sample composition differed from that described by Petrowski et al. [29] with respect to mean age and gender, reliability estimates were only marginally different, with Cronbach's $\alpha(\alpha=.81-.91)$ and split-half reliabilities $(r=.81-.90)$ being slightly higher for the TICS-E [29]. The item scale correlations ranged from $r_{i t}=0.5$ to 0.85 and were therefore higher than for the German TICS version (item scale correlations $r_{i t}=.48$ to .80 ). The item means were similar to the data from the representative German sample [29]. However, the scale scores Work Overload and Pressure to Perform were slightly higher and Social Isolation and Chronic Worrying were slightly lower than in the German reference samples. Overall, the TICS-E showed good psychometric properties.

\section{Limitations}

The sample of the present study does not allow inferences about the US population as a whole because it was drawn from the undergraduate student population, with a low mean age of 19.96 years $(\mathrm{SD}=2.79)$, consisting mostly of female participants $(75.6 \%)$. The socioeconomic background and work experiences of these students are very homogeneous and the variance of chronic work or family stress is limited. In addition, it is likely that these psychology students have experience with answering questionnaires. It is possible that this also affected the evaluation of the psychometric properties of the questionnaire. This limitation is shared with previous studies using questionnaires. Additional limitations regarding questionnaire validity are posed by the use of a rating scale with only five response categories and the suboptimal model fit in the CFA.

\section{Future research indications}

Future studies could test the stability of the chronic stress construct by investigating test-retest reliability and external relationships (criterion validity). In addition, evaluation of the TICS-E in a broader, population-based sample is needed. The best possible comparison would be between representative samples of native speakers of both languages. Additionally, research should explore the convergent validity of the TICS-E by examining associations with other chronic stress measures. Study designs with multiple assessment points would provide the opportunity to compare the stability of the questionnaire's factor structure and determine possible cohort effects. The stress concepts of the questionnaires are based on research conducted in the United States $[2,11]$. The English and German versions of the TICS might also be used to study chronic stress concepts across cultures (German and American).

\section{Conclusion}

We conclude that the psychometric properties and factor structure of the TICS-E are largely comparable to the German version of the TICS in previous studies. The English version meets the relevant requirements of good psychometric properties and factorial validity and is therefore a promising instrument for measuring chronic stress.

\section{Abbreviation}

CFA: Confirmatory Factor Analysis; CFI: Comparative Fit Index; ITC: International Test Commission; MLM: Maximum Likelihood Estimation (MLM); RMSEA: Root mean square error of approximation;

SRMR: Standardized root mean square residual; TICS: Trier Inventory for Chronic Stress; TICS-E: English version of the Trier Inventory for Chronic Stress; TLI: Tucker Lewis Index

\section{Acknowledgements}

The authors would like to thank all the participants of the study.

Funding

There has not been any specific funding.

Availability of data and materials

The datasets used and analyzed during the current study available from the corresponding author on reasonable request.

\section{Authors' contributions}

$M S, E B, K P, A M$, and TR were responsible for the conception and the design of the study as well as the acquisition of the data. KP, EB and SK performed the statistical analyses, interpreted data, and wrote the first and the final version of the manuscript. MS and TR contributed to the interpretation of the data and critically revised the manuscript for intellectual content. All the authors read and approved the final version of the manuscript for publication.

Ethics approval and consent to participate

The study was approved by the institutional review boards of the involved university institutions and all participants provided written informed consent. 


\section{Consent for publication}

Not applicable.

\section{Competing interests}

The authors declare that they have no competing interests.

\section{Publisher's Note}

Springer Nature remains neutral with regard to jurisdictional claims in published maps and institutional affiliations.

\begin{abstract}
Author details
${ }^{1}$ Witten/Herdecke University, Alfred-Herrhausen-Straße 50, 58448 Witten, Germany. ${ }^{2}$ Criminological Research Institute of Lower Saxony, Lützerodestraße 9, 30161 Hannover, Germany. ${ }^{3}$ eResearch Technology, 500 Rutherford Avenue, Boston, MA 02129, USA. ${ }^{4}$ Department of Psychology, Southern Methodist University, 6116 N. Central Expressway, Suite 1160, Dallas, TX 75206, USA. ${ }^{5}$ University Medical Center of the Johannes Gutenberg University Mainz, Langenbeckstraße 1, 55131 Mainz, Germany. ${ }^{6}$ Department of Medical Psychology and Medical Sociology, University of Leipzig, Philipp-Rosenthal-Straße 55, 04103 Leipzig, Germany.
\end{abstract}

Received: 3 November 2017 Accepted: 4 January 2018 Published online: 06 February 2018

\section{References}

1. Abidin R, Flens JR, Austin WG. The parenting stress index. Forensic Uses of Clinical Assessment Instruments. 2006:297-328.

2. Antonovsky A. Unraveling the mystery of health: how people manage stress and stay well. San Francisco: Jossey-Bass; 1987.

3. Becker P. Prävention und Gesundheitsförderung. In: Schwarzer R, editor. Gesundheitspsychologie. Ein Lehrbuch. Göttingen: Hogrefe; 1997. p. 517-34.

4. Becker P, Schulz P, Schlotz W. Persönlichkeit, chronischer Stress und körperliche Gesundheit: Eine prospektive Studie zur Überprüfung eines systemischen Anforderungs-Ressourcen-Modells. Zeitschrift Für Gesundheitspsychologie. 2004; 12(1):11-23. https://doi.org/10.1026/0943-8149.12.1.11.

5. Browne MW, Cudeck R. Alternative ways of assessing model fit. Sage focus editions. 1993;154:136-136.

6. Chandola T, Brunner E, Marmot M. Chronic stress at work and the metabolic syndrome: prospective study. BMJ (Clinical Research Ed). 2006;332(7540): 521-5. https://doi.org/10.1136/bmj.38693.435301.80.

7. Chou CP, Bentler PM, Satorra A. Scaled test statistics and robust standard errors for non-normal data in covariance structure analysis: a Monte Carlo study. The British Journal of Mathematical and Statistical Psychology. 1991; 44(Pt 2):347-57. https://doi.org/10.1111/j.2044-8317.1991.tb00966.x.

8. Cohen S, Edwards JR. Personality characteristics as moderators of the relationship between stress and disorder. In: Advances in the investigation of psychological stress. New York: Neufeld, R. W. J; 1989. p. 235-83.

9. Cohen S, Kamarck T, Mermelstein R. A global measure of perceived stress. J Health Soc Behav. 1983;24(4):385-96. https://doi.org/10.2307/2136404.

10. Cohen S, Kessler RC, Gordon LU. Measuring stress. A guide for health and social scientists. New York: Oxford; 1997.

11. Coie JD, Watt NF, West GS, Hawkins JD, Asarnow JR, Markman HJ, et al. The science of prevention: a conceptual framework and some directions for a National Research Program. Am Psychol. 1993;48(10):1013-22.

12. Eckenrode J, Gore S. Stress between work and family. (Eckenrode J. \& Gore S.). New York: plenum press; 1990.

13. Ehrström S, Kornfeld D, Rylander E, Bohm-Starke N. Chronic stress in women with localised provoked vulvodynia. J Psychosom Obstet Gynaecol. 2009; 30(1):73-9. https://doi.org/10.1080/01674820802604359.

14. Gannon L, Pardie L. The importance of chronicity and controllability of stress in the context of stress-illness relationships. Journal of Behavioral Medicine. 1989; 12(4):357-72. Retrieved from http://www.ncbi.nlm.nih.gov/pubmed/2600964.

15. Hair JF, Black WC, Babin BJ, Anderson RE. Multivariate data analysis. Vectors. 2010; https://doi.org/10.1016/j.ijpharm.2011.02.019.

16. Heim E, Willi J. Psychosoziale Medizin Gesundheit und Krankheit in biopsycho-sozialer Sicht: 2 Klinik und Praxis. Berlin: Springer; 1986.

17. Herbert TB, Cohen S. Stress and immunity in humans: a meta-analytic review. Psychosom Med. 1993;55(4):364-79. https://doi.org/10.1097/ 00006842-199307000-00004.
18. Hu L, Bentler PM. Cutoff criteria for fit indices in covariance structure analysis: conventional criteria versus new alternatives. Struct Equ Model. 1999;6:1-55. https://doi.org/10.1080/10705519909540118.

19. International Test Commission (2005). International Guidelines on Test Adaptation. www.intestcom.org.

20. Karasek R, Theorell T. Healthy work: stress, productivity, and the reconstruction of working life. New York: Basic Books; 1990.

21. Kessler RC, Price RH, Wortman CB. Social factors in psychopathology: stress, social support, and coping processes. Annu Rev Psychol. 1985; http://doi. org/doi:10.1146/annurev.ps.36.020185.002531.

22. Krantz DS, Contrada RJ, Durel LA, Hill DR, Friedler E, Lazar JD. Comparative effects of two beta-blockers on cardiovascular reactivity and type a behavior in hypertensives. Psychosomatic Medicine. 1988;50(6):615-26. Retrieved from http://www.ncbi.nlm.nih.gov/pubmed/2853406.

23. Lepore SJ. Measurement of chronic stressors. In: Cohen S, Kessler RC, Gordon LU, editors. Measuring stress: a guide for health and social scientists. London: Oxford University Press; 1997. p. 102-20.

24. Lepore SJ, Evans GW, Palsane MN. Social hassles and psychological health in the context of chronic crowding. J Health Soc Behav. 1991;32(4):357-67. https://doi.org/10.2307/2137103.

25. Marsh H, Hau K-T, Wen Z. In search of golden rules: comment on hypothesistesting approaches to setting cutoff values for fit indexes and dangers in overgeneralizing Hu and Bentler's (1999) findings. Struct Equ Model Multidiscip J. 2004;11(3):320-41. https://doi.org/10.1207/s15328007sem1103 2

26. McEwen, B. S. B. B. S. B. (1998). Seminars in Medicine of the Beth Israel Deaconess Medical Center: Protective and damaging effects of stress mediators 1998, 338(1), 171-179. https://doi.org/10.1056/NEJM199710023371407.

27. McGonagle KA, Kessler RC. Chronic stress, acute stress, and depressive symptoms. Am J Community Psychol. 1990;18(5):681-706. https://doi.org/10.1007/BF00931237.

28. Pearlin LI. The sociological study of stress. J Health Soc Behav. 1989;30(3): 241-56. https://doi.org/10.2307/2136956.

29. Petrowski K, Paul S, Albani C, Brähler E. Factor structure and psychometric properties of the trier inventory for chronic stress (TICS) in a representative German sample. BMC Med Res Methodol. 2012;12(1):42. https://doi.org/10. 1186/1471-2288-12-42

30. Pratt $\mathrm{L}$, Barling J. Differentiating between daily events, acute and chronic stressors: a framework and its implications. In: Hurrell J, Murphy L, Sauter S, Cooper C, editors. Occupational stress: issues and developments in research. New York; 1988. p. 41-53.

31. Roohafza H, Talaei M, Sadeghi M, Mackie M, Sarafzadegan N. Association between acute and chronic life events on acute coronary syndrome A Case-Control Study. Journal of Cardiovascular Nursing. 2010;25(5):E1-7. https://doi.org/10.1097/JCN.0b013e3181d81799.

32. Rosseel Y. Lavaan: an R package for structural equation modeling. J Stat Softw. 2012;48(2):1-36. https://doi.org/10.18637/jss.v048.i02.

33. Scheuch K, H S. Mensch unter Belastung. Stress als ein humanwissenschaftliches Integrationskonzept. Berlin: Deutscher Verlag der Wissenschaften; 1990.

34. Schulz P, Hellhammer J, Schlotz W. Arbeitsstress, sozialer Stress und Schlafqualität: Differentielle Effekte unter Berücksichtigung von Alter, Besorgnisneigung und Gesundheit. Zeitschrift Für Gesundheitspsychologie. 2003;11(1):1-9. https://doi.org/10.1026//0943-8149.11.1.1.

35. Schulz P, Schlotz W, Becker P. Trierer Inventar zum chronischen Stress (TICS). Göttingen: Hogrefe; 2004.

36. Schulz P, Schönpflug W. Regulatory activity during states of stress. Series in Clinical \& Community Psychology: Achievement, Stress, \& Anxiety. 1982:51-73.

37. Werner EE. Risk and resilience in individuals with learning disabilities: lessons learned from the Kauai longitudinal study. Learning Disabilities Research \& Practice. 1993;8(1):28-34.

38. Wheaton B. Sampling the stress universe. In: Avison WR, Gotlib $H_{\text {, editors. }}$ The Plenum series on stress and coping. Stress and mental health: Contemporary issues and prospects for the future; 1994. p. 77-114. https:// doi.org/10.1007/978-1-4899-1106-3_4.

39. Wheaton B. The nature of chronic stress. In: Gottlieb B.H. (eds) Coping with Chronic Stress (43-73). The springer series on stress and coping. Boston, MA: springer; 1997. 